\title{
Synthesis, Vibrational Spectroscopy and Optical Study of Bi-Tetrabutylphosphonium Hexachlorostannate
}

\section{Mbarek ( $\boldsymbol{D}$ ineeesa@outlook.fr)}

University of Sfax

\section{Ben Gzaiel}

University of Sfax

\section{A. Oueslati}

University of Sfax

M Gargouri

University of Sfax

\section{Research Article}

Keywords: bi-tetrabutylphosphonium hexachlorostannate, Phase transitions, optical properties.

Posted Date: July 26th, 2021

DOI: https://doi.org/10.21203/rs.3.rs-609732/v1

License: (a) (i) This work is licensed under a Creative Commons Attribution 4.0 International License. Read Full License 


\title{
Synthesis, vibrational spectroscopy and optical study of bi-tetrabutylphosphonium hexachlorostannate
}

\author{
I. Mbarek, M. Ben Gzaiel, A. Oueslati, M Gargouri \\ Laboratory for spectroscopic characterization and optics of materials, Faculty of Sciences, University of Sfax, \\ B.P. 1171, 3000 Sfax, Tunisia
}

\begin{abstract}
:
The single crystals of bi-tetrabutylphosphonium hexachlorostannate were grown by solvent evaporated method and characterized by X-ray powder diffraction, Raman spectroscopy and optical study. The X-ray powder diffraction indicates that it was crystallized in the monoclinic system, with $\mathrm{C} 2 / \mathrm{c}$ space group. Besides, temperature-controlled X-ray diffraction show that the $\left[\mathrm{P}\left(\mathrm{C}_{4} \mathrm{H}_{9}\right)_{4}\right]_{2} \mathrm{SnCl}_{6}$ compound indicate the presence of two phase transitions detected at 388 and $403 \mathrm{~K}$. The evolution of Raman line shifts, " $v$ ", and the half-width, " $\Delta v$ ", versus temperature show some singularities associated with the transitions, suggesting the important role of the anionic parts $\left(\left(\mathrm{SnCl}_{6}\right)^{2-}\right)$. Besides, the results of the Raman study confirms the conclusion drawn from the X-ray powder diffraction measurements that the phase transition are located near $388 \mathrm{~K}$ and $403 \mathrm{~K}$.

Furthermore, an optical absorption measurement confirms the semiconductor nature with a band gap equal to $3.46 \mathrm{eV}$.

Keywords: bi-tetrabutylphosphonium hexachlorostannate, Phase transitions, optical properties.
\end{abstract}

\section{Introduction:}


The field of organic-inorganic hybrid materials has been growing intensively during the past 20 years and is certainly nowadays one of the major fields of research and unambiguously one of the most exciting. Moreover, the need for always better materials for complex devices with improved properties and multifunctional responses is a perpetual demand, which often can be fulfills by the use of hybrid materials.

In addition to that, these materials are both fundamentally and technologically important because of their structural versatility and interesting/unique properties that result from the incorporation of both inorganic and organic components in a single crystal lattice. [1,2]

Particularly, hybrid organic-inorganic compounds based on halogenometallates such as Sb, Sn, and $\mathrm{Bi} \ldots . .[3,4]$ have been widely explored due to their interesting physical properties and their application in new technology such as the manufacture of devices as well as their ability to present phase transitions. In fact, much spate of interest has been devoted to the development of a new multifunctional generation of organic-inorganic structures with the general formula $\mathrm{A}_{2} \mathrm{SnCl}_{6}(\mathrm{~A}=$ organic cation $)$ displaying new interesting properties. In the case of tin halide systems, some interest have been widely studied as semiconducting components [5] in organic-inorganic hybrid semiconductors with potential applications in display and storage technologies because of their stable exciton and superior carrier mobility [6]. In fact, the Sn (II) represents a potential class of materials with unusual structural archetypes. In the present study, we report on the investigation of the phase transitions in bitetrabutylphosphonium hexachlorostannate as a function of temperature that is based on X-ray powder diffraction and Raman scattering. Thus, optical investigation was carried out.

\section{Experimental details:}

\subsection{Synthesis}

The synthesis of the bi-tetrabutylphosphonium hexachlorostannate was carried out using the Solvent evaporation method, which is a similar preparation procedure of other hybrids 
compounds $[7,8]$. It was prepared in two steps. Firstly, $\mathrm{SnCl}_{2}(98 \%$; SIGMA ALDRICH) dissolved in concentrated $\mathrm{HCl}$. Secondly, the obtained solution was added in molar ratio of 1:1 to $\left[\mathrm{P}\left(\mathrm{C}_{4} \mathrm{H}_{9}\right)_{4}\right] \mathrm{Cl}$ (Purity 97\%; FLUKA). After few days and at room temperature a good quality of transparent single crystal was obtained. It's were washed by absolute ethanol and dried in vacuum desiccators.

\subsection{Characterization}

The phase purity and homogeneity of the as-prepared powder was first checked by recording X-ray powder diffraction (XRPD) pattern at room temperature on a PANalytical $\theta / \theta$ BraggBrentano, Empyrean diffractometer $\left(\mathrm{Cu} \mathrm{K}_{1+2}\right.$ radiations) equipped with the PIXcel ${ }^{1 \mathrm{D}}$ detector. The XRD pattern was recorded in the scattering angle range, [5- $60^{\circ}$ ] with a 0.0131 step size, for a total acquisition time of $10 \mathrm{~h}$. The Rietveld refinement of the XRD profile was performed using the Fullprof program [9].

Raman scattering spectra was collected with a T64000 Raman spectrometer (HoribaJobin Yvon), using the $514.53 \mathrm{~nm}$ radiation of an $\mathrm{Ar} / \mathrm{Kr}$ laser as excitation. All measurements were done under microscope using $\mathrm{x} 50 \mathrm{LF}$ objective in back scattering geometry on transparent single crystal using the parallel polarization, and collected in the wavenumber range $100-500 \mathrm{~cm}^{-1}$. The crystals were set in a Linkam heating stage for measurements as a function of temperature up to $433 \mathrm{~K}$. In order to quantitatively analyze the evolution of Raman bands versus temperature, each spectrum were analyzed by means Labspec software based on Gaussian and Lorentzian shapes.

The optical properties were measured at room temperature, using a UV-3101PC scanning spectrophotometer that has a dual-beam monochromator, covering a spectrum from $200 \mathrm{~nm}$ to $800 \mathrm{~nm}$ and using two sources: (i) xenon lamp for the UV-visible domain and (ii) halogen 
lamp for the infrared range. This technique makes it possible to determine the absorbance (A) and the reflectance $(\mathrm{R})$.

\section{Results and discussion}

\subsection{Temperature dependence of $X$-ray diffraction}

Fig. 1 shows the XRD pattern of $\left[\mathrm{P}\left(\mathrm{C}_{4} \mathrm{H}_{9}\right)_{4}\right]_{2} \mathrm{SnCl}_{6}$ compound at room temperature. All Bragg peaks were successfully indexed and satisfactorily modeled, thus confirming the high purity of the sample. The X-ray powder diffraction diagram showed that it was crystallizes in the centrosymmetric, monoclinic system, (C2/c space group) with the following unit cell parameters: $a=14.4125 \AA, b=18.7173 \AA, c=17.5157 \AA$, and $\beta=113.15^{\circ}$. These values are in good agreement from XRD data collected on a single crystal of $\left[\mathrm{P}\left(\mathrm{C}_{4} \mathrm{H}_{9}\right)_{4}\right]_{2} \mathrm{SnCl}_{6}[10]$. The conventional reliability factors of the refinement are $\mathrm{Rp}=4.45 \%, \mathrm{Rwp}=5.28 \%$, Rexp=3.59\% and $\chi^{2}=2.16$.

In order to learn more information about the mechanism of phase transition in $\left[\mathrm{P}\left(\mathrm{C}_{4} \mathrm{H}_{9}\right)_{4}\right]_{2} \mathrm{SnCl}_{6}$, we have undertaken the evolution of the X-ray powder diffraction in the temperature range from $293 \mathrm{~K}$ to $413 \mathrm{~K}$. X-rays diffraction at selected temperatures of the sample is reported in Fig. 2. An overview of this figure, the positions and intensities of the peaks in the XRD patterns measured at $393 \mathrm{~K}$ and $413 \mathrm{~K}$ were greatly changed. Particularly, at $393 \mathrm{~K}$, we observe a large decrease in the intensities for all reflections. When the temperature attends $413 \mathrm{~K}$, we note a decrease in the intensities of some peaks ("A" and "B")

while the emergence of novel peaks for higher angles ("C"). This suggests that the approximate structures of the high-temperature and low-temperature phases are so different. These changes correspond to the thermal phase transitions detected using DSC. So, all phase transitions that were detected in the DSC [10], could be observed by a change in the crystal structure in the HT-XRPD diagram 


\subsection{Temperature evolution of the Raman spectra of the $\left[\mathrm{P}\left(\mathrm{C}_{4} \mathrm{H}_{9}\right)_{4}\right]_{2} \mathrm{SnCl} \mathrm{C}_{6}$ crystals}

In order to get more about on the phase transitions mechanisms in $\left[\mathrm{P}\left(\mathrm{C}_{4} \mathrm{H}_{9}\right)_{4}\right]_{2} \mathrm{SnCl}_{6}$ the temperature evolution of the Raman bands has been investigated in the $293 \mathrm{~K}-433 \mathrm{~K}$ range. The tentative assignments at room temperature for a majority of the vibrational bands using previously reported data in the literature on similar compounds are: $\mathrm{NH}_{3}\left(\mathrm{CH}_{2}\right)_{3} \mathrm{NH}_{4} \mathrm{SnCl}_{6}$ [11], [ $\left.\mathrm{NH}_{3}\left(\mathrm{CH}_{2}\right)_{5} \mathrm{NH}_{3}\right] \mathrm{SnCl}_{6}$ [12], $\mathrm{NH}_{3}\left(\mathrm{CH}_{2}\right)_{3} \mathrm{NH}_{3} \mathrm{SnCl}_{6}$ [12], $\mathrm{NH}_{3}\left(\mathrm{CH}_{2}\right)_{4} \mathrm{NH}_{3} \mathrm{SnCl}_{6}[12]$, $\mathrm{NH}_{3}\left(\mathrm{CH}_{2}\right)_{6} \mathrm{NH}_{3} \mathrm{SnCl}_{6}[12]$ and $\left[\mathrm{C}_{2} \mathrm{H}_{4}-\mathrm{N}_{3}\right]_{2} \mathrm{SnCl}_{6} \cdot \mathrm{H}_{2} \mathrm{O}$ [13] and are listed in Table 1. Fig.3 shows the temperature dependent Raman spectra of the $\left[\mathrm{P}\left(\mathrm{C}_{4} \mathrm{H}_{9}\right)_{4}\right]_{2} \mathrm{SnCl}_{6}$. A deconvolution of all spectra was necessary to follow the temperature dependence of the wavenumber and half maximum. This deconvolution was carried out by means of Labspec software with a combination of two Lorentzian and Gaussian functions. An example of the deconvolution of spectrum recorded at $303 \mathrm{~K}$ in the frequency range $100-500 \mathrm{~cm}^{-1}$ is shown in fig. 4 .

The positions and width at half maximum for selected lines, obtained in this range where the anionic part is found are shown in fig.5 and fig.6, respectively. Significant changes are observed in the vicinity of $388 \mathrm{~K}$ and $403 \mathrm{~K}$ where the phase transitions have been detected, which is in good agreement with DSC and electrical measurements [10]. A very important change is observed in the broad and weak bands located near 238 and 253 $\mathrm{cm}^{-1}$ assigned to $v_{\mathrm{s}}(\mathrm{SnCl})$ and $v_{\text {as }}(\mathrm{SnCl})$ respectively. These two bands merged into a single line in the first transition $(388 \mathrm{~K})$ and are broke into three bands after the second transition (403K). While the half maximum of them decreased by $14 \mathrm{~cm}^{-1}$ above $403 \mathrm{~K}$. The very strangest line at $309 \mathrm{~cm}^{-1}$ associated with $v_{5}(\mathrm{Cl}-\mathrm{Sn}-\mathrm{Cl})$ mode underwent a shift toward high frequency by $4 \mathrm{~cm}^{-1}$ above the second transition, with a half maximum increase by $6 \mathrm{~cm}^{-1}$ at $\mathrm{T}_{1}$ but it was decrease by $12 \mathrm{~cm}^{-1}$ after $\mathrm{T}_{2}$. Another line in the vicinity of $156 \mathrm{~cm}^{-1}$ attributed to $v_{1}(\mathrm{SnCl})$ undergoes a shift toward high frequency by $3 \mathrm{~cm}^{-1}$ above the second transition, with a line width increase by $10 \mathrm{~cm}^{-1}$ at $388 \mathrm{k}$ whereas it was decrease by $13 \mathrm{~cm}^{-1}$ after $403 \mathrm{~K}$. 
These observations are indicative of strong contributions of the anionic parts to the mechanism of phase transitions.

\section{3. $\quad U V$-visible spectroscopy:}

\subsubsection{Optical absorbance spectra}

At room temperature, the experimental UV-Vis absorption spectrum of $\left[\mathrm{P}\left(\mathrm{C}_{4} \mathrm{H}_{9}\right)_{4}\right]_{2} \mathrm{SnCl}_{6}$ compound in the region 200-800 $\mathrm{nm}$ is shown in Fig.7. It is clearly seen from this figure that the absorption coefficient tends to decrease exponentially as the wavelength increases. This is a typical behavior for numerous semiconductors and can be due to many reasons, such as internal electric fields within the crystal, deformation of lattice due to strain caused by imperfection and inelastic scattering of charge carriers by phonons [14]. The absorption spectrum showed three distinct peaks located at 238, 287 and $386 \mathrm{~nm}$. The appearance of a huge decrease near the absorption edge towards $287 \mathrm{~nm}$ in this spectral range was due to the excitation of an electron from the valence band to the conduction band, which meant band-to-band transition in the octahedron $\left[\mathrm{SnCl}_{6}\right]$. It was mainly attributed to an electronic transition from the valence band represented by the chlorine orbital ( $3 p)$ to the conduction band represented by the tin orbital $(5 \mathrm{p})$. The other two peaks which were observed at $238 \mathrm{~nm}$ and $386 \mathrm{~nm}$ respectively were probably due to a non-radiative exciton absorption in the forbidden energy band. The deconvolution of the absorption spectrum (fig.7) is added in order to clearly show the three peaks of this spectrum.

\subsubsection{Optical band gap.}

The optical band gap is an important factor in several fields of science including photovoltaics, solar cells, lasers, photoluminescence, or diodes. [15, 16]

Fig.8 shows the plot of $[\alpha h v)]^{1 / 2}$ versus the photon energy hv which leads to the Eg value by a linear fit. 
The Kubelka-Munk method is used to analyze the reflection spectrum of the scattered light. It is widely used for semi-reflective materials in the visible field. The Kubelka-Munk equation is given by the following form:

$$
F(R)=\frac{(1-R)^{2}}{2 R}=\frac{K}{S}
$$

Where $\mathrm{R}, \mathrm{K}$ and $\mathrm{S}$ are the diffuse reflectance, the absorption coefficient and the scattering coefficient, respectively. $\mathrm{F}(\mathrm{R})$ values are converted into the linear absorption coefficient by the following relation: $[17,18]$

$$
\alpha=\frac{F(R)}{t}
$$

Where $\mathrm{t}$ is the thickness of the compound

It is well known that the optical transitions in semiconductor materials take place through direct and indirect transitions. The value of the optical band gap Eg can be calculated using the fundamental absorption, which corresponds to the electron excitation from the valence band to the conduction band. The band gap evolution was estimated based on the Tauc plot method, expressed as: [19]

$$
\alpha h v=A(h v-E g)^{n}
$$

Where $(\mathrm{h} v)$ is the energy of the incident photons, A is a constant characteristic of the material, Eg is the optical energy gap, $\alpha$ is the absorption coefficient, and $\mathrm{n}$ is an empirical exponent, which characterizes the type of optical transition during the absorption process. The transition is called direct, if the extremities of VB (valence band) and CB (conduction band) lie at the same K-space, however, the transition is called indirect, if the transition is possible only with phonon assisted. Thus, the value of (n) may be $1 / 2$ and 2, corresponding to 
the allowed direct and indirect [20]. The energy of the incident photon is calculated using the following equation: [21]

$$
h v=\frac{1240}{\lambda(n m)}
$$

After plotting $(\alpha h v)^{2}$ and ( $\left.\alpha \mathrm{h} v\right)^{1 / 2}$ in function of the photon energy (hv), it was found that the most suitable and adequate plot was when $\mathrm{n}=2$. $\mathrm{Eg}$ was found herein equal to $3.46 \mathrm{eV}$. The value of the gap energy show that this material can be classified as semiconductor and it's smaller than $\mathrm{Cs}_{2} \mathrm{SnCl}_{6}$ 's gap energy value. [22]

\subsubsection{Urbach energy:}

The Urbach energy characterizes the disorder of a material and corresponds to transitions between extended states of the valence band and localized states of the conduction band. From the variation of the absorption coefficient, it is possible to deduce the disorder in the compound, given by this equation: [23]

$$
\alpha=\alpha_{0} \exp \left(\frac{h v}{E_{u}}\right)
$$

Where $\alpha_{0}$ is a constant and $E_{U}$ is an energy, which is interpreted as the width of the tail of localized states in the forbidden band gap, $v$ is the frequency of radiation, and $h$ is Planck's constant. Fig.9 shows the theoretical adjustment of the plot $\ln (\alpha)$ as function of energy $(h v)$. The Urbach parameter was calculated by the inverse of the slope to the curve. The value of this energy was equal to $0.27 \mathrm{eV}$, which is weaker than $\mathrm{Cs}_{2} \mathrm{SnCl}_{6}$ 's Urbach energy [22]. This explains the good crystal quality of this material and confirms the result found by XRD [24].

\subsubsection{The extinction coefficient}


The extinction coefficient $(\mathrm{K})$ is linked to the absorption coefficient by the following equation:

$$
K=\frac{\alpha \lambda}{2 \pi}
$$

Where $\lambda$ is the wavelength of the incident photons. Fig.10 represents the variation of $\mathrm{k}$ in function of $\lambda$ for the incident electromagnetic radiation. This low value confirms the good transparency of our material. [25]

\section{Conclusion}

In summary, the $\left[\mathrm{P}\left(\mathrm{C}_{4} \mathrm{H}_{9}\right)_{4}\right]_{2} \mathrm{SnCl}_{6}$ organic-inorganic compound has been successfully synthesized by the Solvent evaporation method. X-ray diffraction shows its monoclinic structure with $\mathrm{C} 2 / \mathrm{c}$ space group. The Temperature dependence of X-ray diffraction suggests that the approximate structures of the high and low-temperature phases are not the same, which indicate the existence of two phase transitions at $388 \mathrm{k}$ and $403 \mathrm{k}$. Besides, the Raman spectroscopic study clearly shows spectacular temperature changes of the internal vibrations modes of the anion, these changes confirm the important role played by the anionic part in the phase transitions mechanism. UV-Vis spectroscopy was investigated to decide certain main parameters, for example, the band gap energy and the Urbach energy. The optical properties show that the entitled compound has a semiconducting character for which the gap energy is $3.46 \mathrm{eV}$. 


\section{References:}

[1] Li, J. Zhang, R. in Prog, Inorg. Chem.42 (2011) 445-504.

[2] Bian.S.D, Wu.H.B, Wang,Q.M. Chem. Int. Ed.48 (2009) 5363-5365.

[3] W. H. H. J De Beer, A. M. Heyns, P. W. Richter, J. B. Clark. Sol.State.Chem. 36 (1981) $171-178$

[4] Y. Abid, A. Trigui, A. Mlayah, E.K. Hlil, Y. Abid, Results. Phys. 2 (2012) 71-76.

[5] J.L. Kuntson, J.D. Martin, D.B. Mitzi. Tuning the band gap in hybrid tin iodide perovskite semiconductors using structural Templating, Inorg.Chem..3344. (2005) 4699-4705.

[6] C.R. Kagan, D.B. Mitzi, C.D. Dimitrakopoulos, Organic-inorganic hybrid materials as semiconducting channels in thin-film field-effect transistors, Science. 286(1999) 945-947.

[7] Z. Warnke, E. Styczen, D. Wyrzykowski, A. Sikorski, J. Kłak, J. Mrozinski, Struct Chem $21(2010)$ 285-289.

[8] N. Hannachi , A. Bulou , C. Chassenieux , K. Guidara , F. Hlel ,Phys A 390 (2011) 2987-2994.

[9] M. Sindhu, N. Ahlawat, S. Sanghi, A. Agarwal, R. Dahiya, N. Ahlawat, Curr Appl Phys 40 (2012) 14-29.

[10] I. Mbarek, M. B. Gzaiel, A. Oueslati, S. Auguste, J. Lhoste, and M. Gargouri, Mol. Struct. 20 (2020) 129-361.

[11] M. Elyoubi, A. Ouasri, H. Jeghnou, A. Rhandour, M-C. Dhamelincourt, P. Dhamelincourt, A. Mazzah, Raman. Spectrosc. 35 (2004) 1056-1062.

[12] A. Ouasri, M. S. D. Elyoubi, T. Guedira, A. Rhandour, T. Mhiri, A. Daoud, Spectrochim. Acta. A. 57 (2001) 2593-2598.

[13] M. Daszkiewicz, Mol. Struct. 1032 (2013) 56-61.

[14] J. Tarasiewicz, R. Jakubas, J. Baran, Mol. Struc. 614 (2002) 333-338. 
[15] J. Lv, M. Xu, S. Lin, X. Shao, X. Zhang, Y. Liu, Y. Wang, Z. Chen, Y. Ma, Nanomater. Energy 51 (2018) 489-495.

[16] N. Kobayashi, H. Kuwae, J. Oshima, R. Ishimatsu, S. Tashiro, T. Imato, C. Adachi, S. Shoji, J. Mizuno, Lumin. 200 (2018) 19-23.

[17] E. Yassitepe, Z. Khalifa, G. H. Jaffari, C.-S. Chou, S. Zuluqar, M. I. Sarwar and S. I. Shah, Powder. Technol 201 (2010) 27-34.

[18] S. Gagandeep, B. S. L. Kulwant and H. S. Sahota, Nucl. Sci. Eng 134 (2000) 208-217.

[19] J. Tauc and A. Menth, Non-Cryst.Solids, 10 (1972) 569- 585.

[20] G.S. Shahane, B.M. More, C.B. Rotti, L.P. Deshmukh, Mater. Chem. Phys. 47 (1997) 263-267.

[21] A.Kaltzoglou, M.Antoniadou, A.G.Kontos, C.C.Stoumpos, D.Perganti, E.Siranidi, V.Raptis, K.Trohidou, V.Psycharis, M.G.Kanatzidis, P.Falaras, Phys. Chem. C 120 (2016) $11777-11785$

[22] D. Bhattacharya, S. Chaudhuri, Pal, Vacuum 43 (1992) 202-313.

[23] F. Urbach, Phys. Rev. 92 (1953) 1324-1334.

[24] Lefi. R, Ben Naser. F, and Guermazi. H, Alloys and Compnds, 696 (2017) 1244-1254.

[25] R. Kalthoum, M.Ben Bechir, and A.Ben Rhaiem, A, Physica E Low Dimens. Syst. Nanostruct. 124 (2020) 114-235. 


\section{Figure caption:}

Fig.1: X-ray diffractogram compound at room temperature of the $\left[\mathrm{P}\left(\mathrm{C}_{4} \mathrm{H}_{9}\right)_{4}\right]_{2} \mathrm{SnCl}_{6}$ compound

Fig.2: HT-XRD patterns of the $\left[\mathrm{P}\left(\mathrm{C}_{4} \mathrm{H}_{9}\right)_{4}\right]_{2} \mathrm{SnCl}_{6}$ compound.

Fig.3: Temperature evolution of the Raman spectra in the $100-500 \mathrm{~cm}^{-1}$ frequency range.

Fig.4: Deconvolution of the Raman spectrum at $\mathrm{T}=303 \mathrm{~K}$ in the $100-500 \mathrm{~cm}^{-1}$ spectral range.

Fig.5: Temperature dependence of the position of the hexachlorostannate anions bands.

Fig.6: Temperature dependence of the half-widths of the hexachlorostannate anions bands

Fig.7: Optical absorption spectrum of the $\left[\mathrm{P}\left(\mathrm{C}_{4} \mathrm{H}_{9}\right)_{4}\right]_{2} \mathrm{SnCl}_{6}$ compound.

Fig.8: Plot of $(\alpha h v)^{1 / 2}$ versus $(h v)$ of the $\left[\mathrm{P}\left(\mathrm{C}_{4} \mathrm{H}_{9}\right)_{4}\right]_{2} \mathrm{SnCl}_{6}$ compound.

Fig.9: Plot of $\operatorname{Ln}(\alpha)$ versus $(\mathrm{h} v)$ of the $\left[\mathrm{P}\left(\mathrm{C}_{4} \mathrm{H}_{9}\right)_{4}\right]_{2} \mathrm{SnCl}_{6}$ compound.

Fig.10: Dispersion curve of extinction coefficient $k$ as a function of wavelength.

\section{Table caption:}

Table 1: Tentative assignments of the bands observed in the Raman spectrum of the anionic part of the $\left[\mathrm{P}\left(\mathrm{C}_{4} \mathrm{H}_{9}\right)_{4}\right]_{2} \mathrm{SnCl}_{6}$ compound. 
Figures

Fig.1

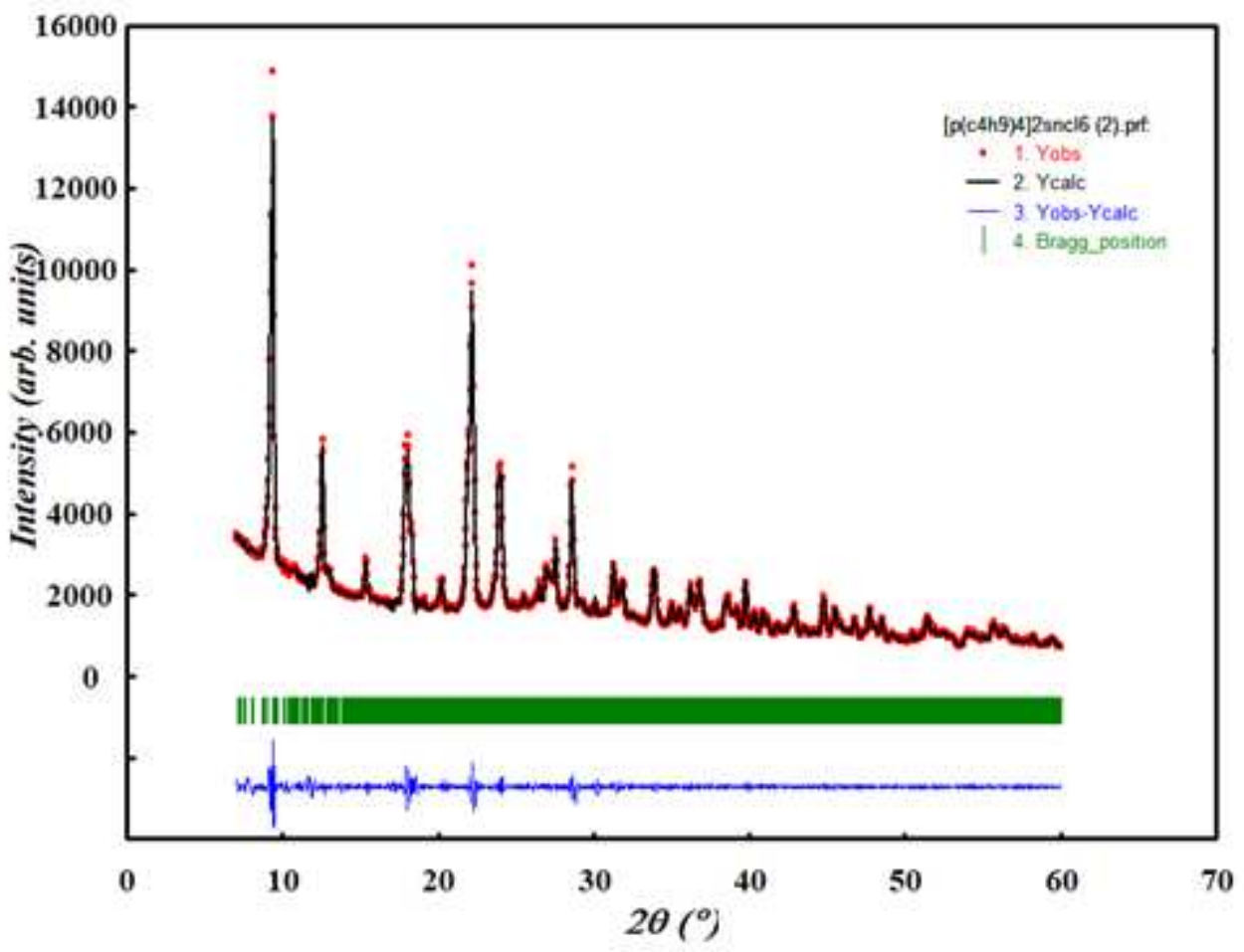

Figure 1

X-ray diffractogram compound at room temperature of the $[\mathrm{P}(\mathrm{C} 4 \mathrm{H} 9) 4] 2 \mathrm{SnCl} 6$ compound 
Fig.2

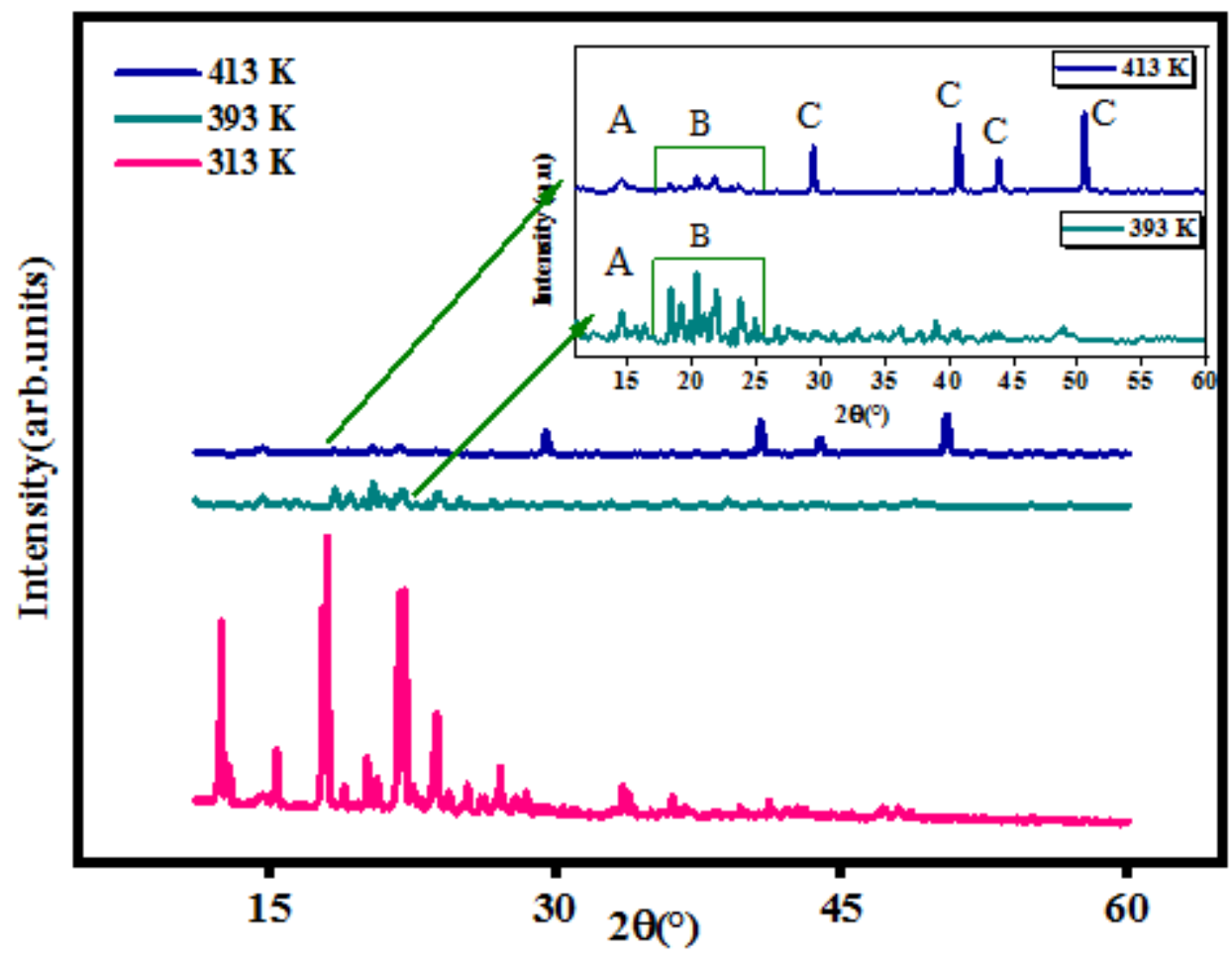

Figure 2

HT-XRD patterns of the $[\mathrm{P}(\mathrm{C} 4 \mathrm{H} 9) 4] 2 \mathrm{SnCl} 6$ compound.

Fig.3

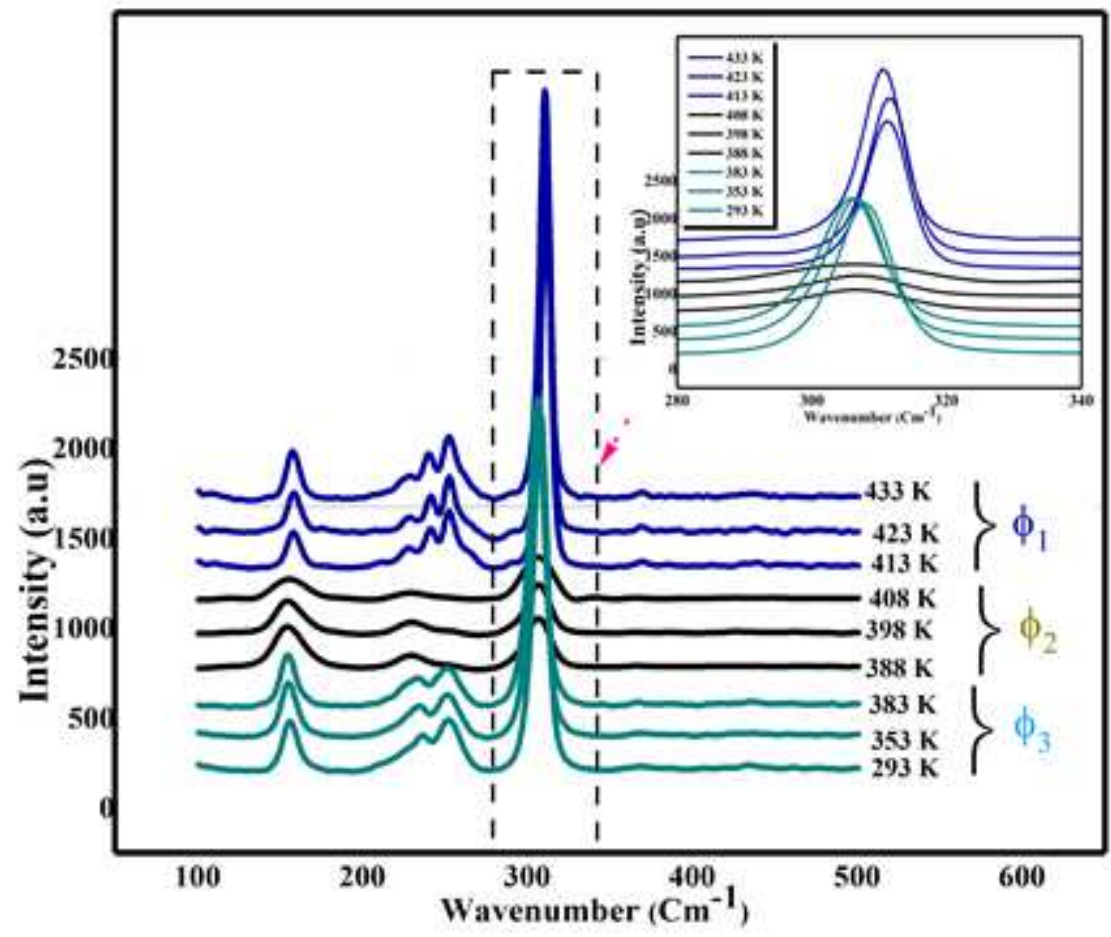


Figure 3

Temperature evolution of the Raman spectra in the $100-500 \mathrm{~cm}-1$ frequency range.

Fig.4

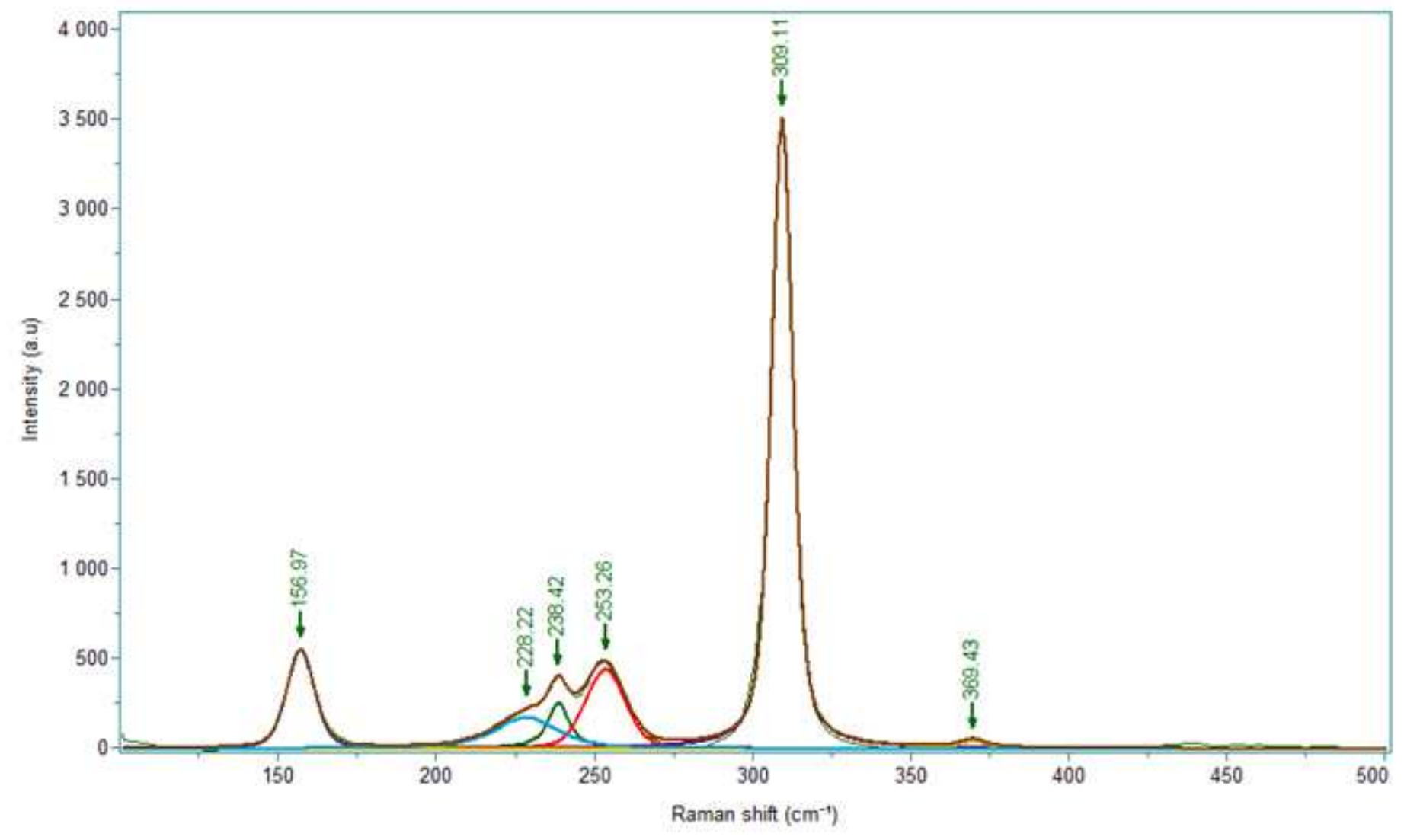

Figure 4

Deconvolution of the Raman spectrum at $\mathrm{T}=303 \mathrm{~K}$ in the $100-500 \mathrm{~cm}-1$ spectral range. 
Fig.5

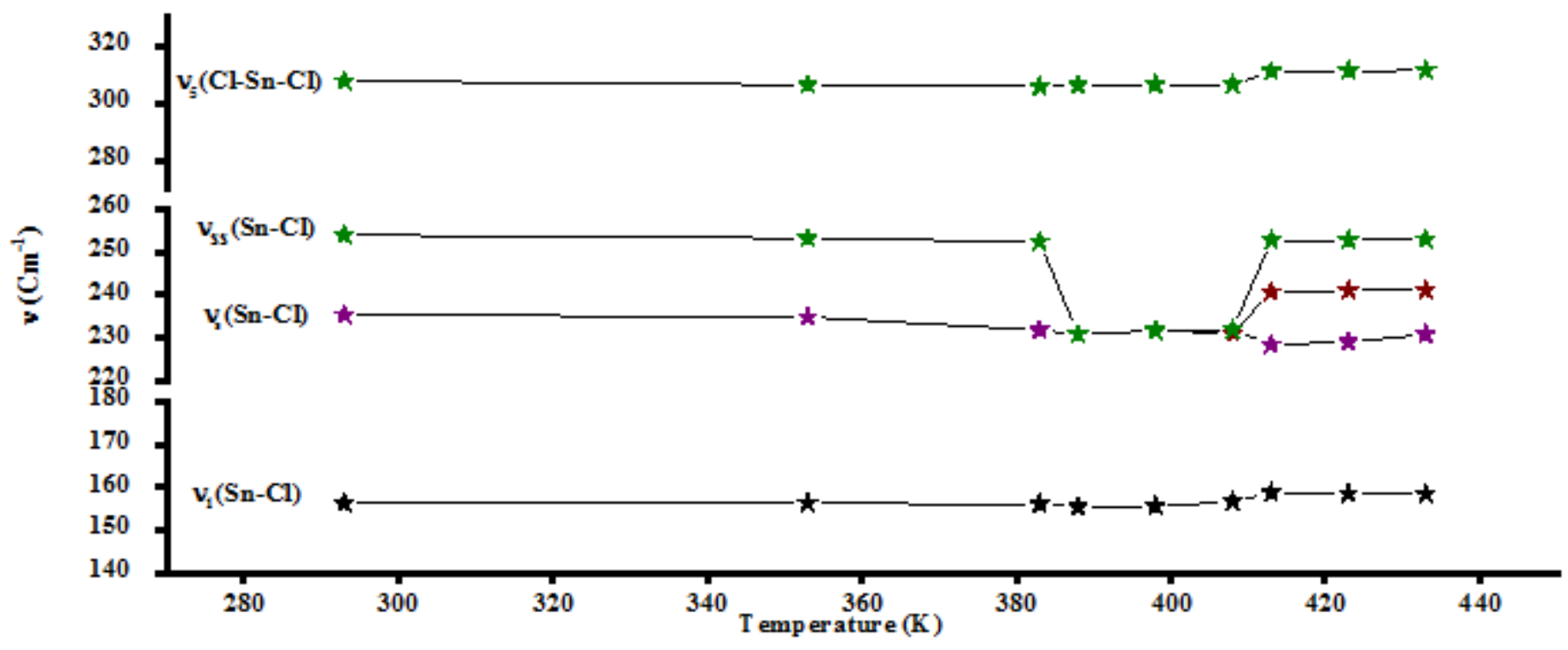

\section{Figure 5}

Temperature dependence of the position of the hexachlorostannate anions bands.

Fig.6

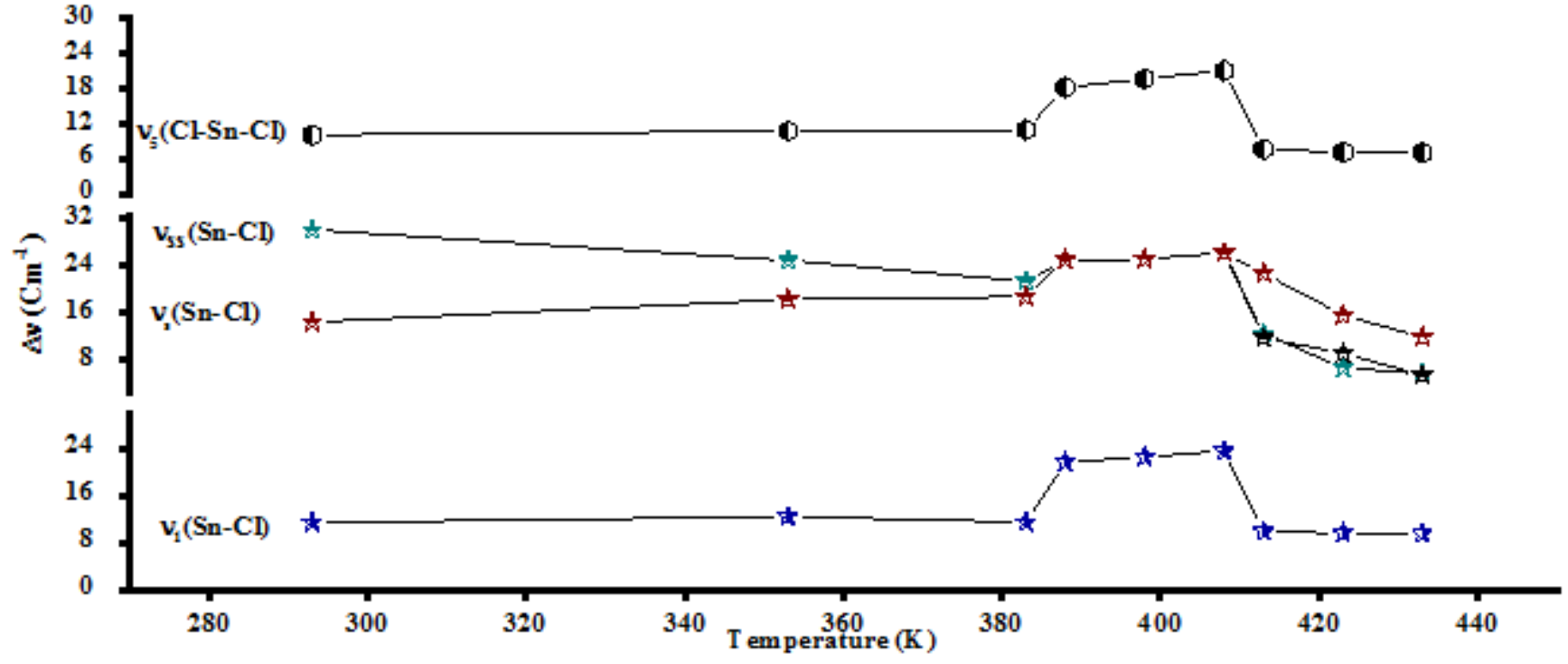

Figure 6

Temperature dependence of the half-widths of the hexachlorostannate anions bands 
Fig.7

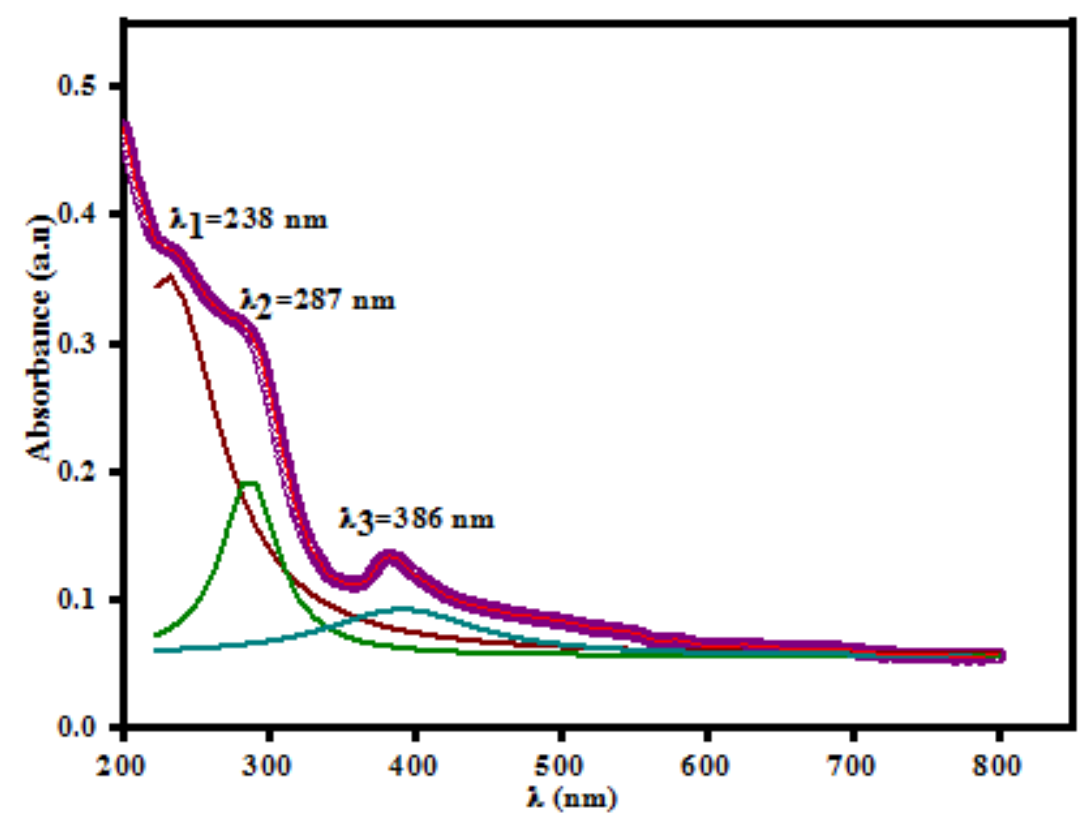

Figure 7

Optical absorption spectrum of the $[\mathrm{P}(\mathrm{C} 4 \mathrm{H} 9) 4] 2 \mathrm{SnCl} 6$ compound.

Fig.8

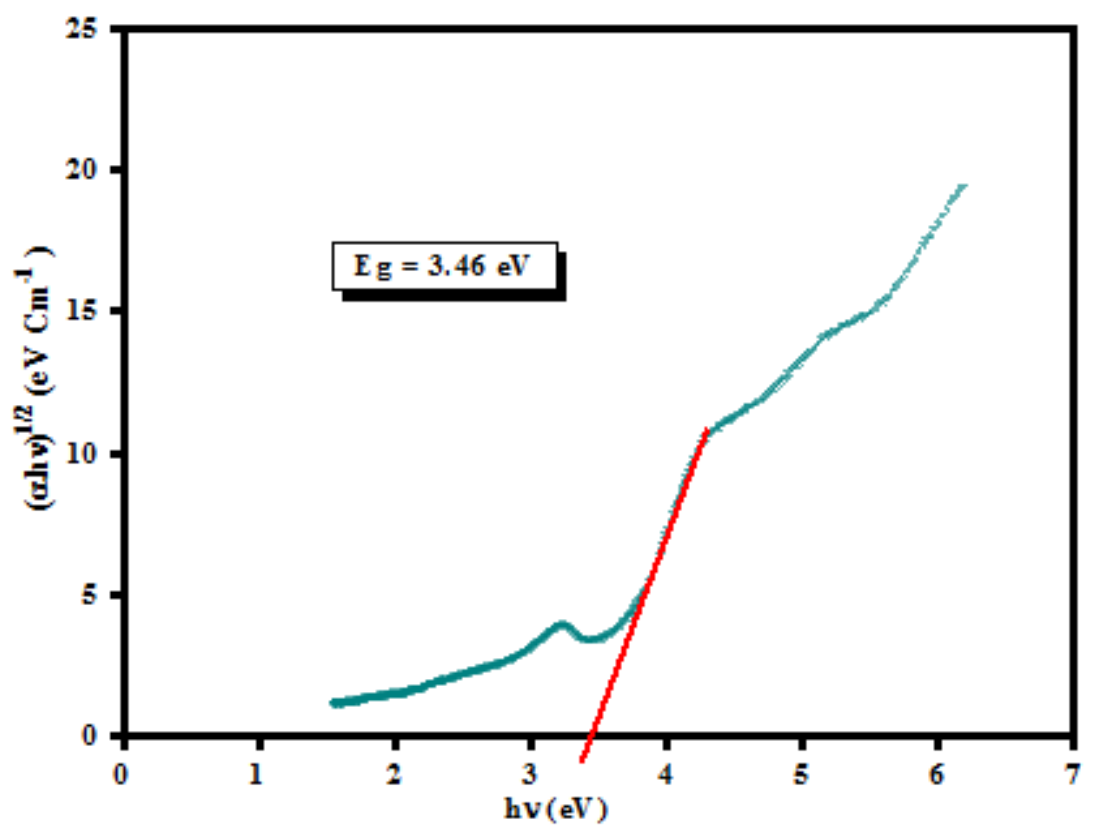

Figure 8 
Plot of (ahv) 1/2 versus (hv) of the $[\mathrm{P}(\mathrm{C} 4 \mathrm{H} 9) 4] 2 \mathrm{SnCl6}$ compound.

Fig.9

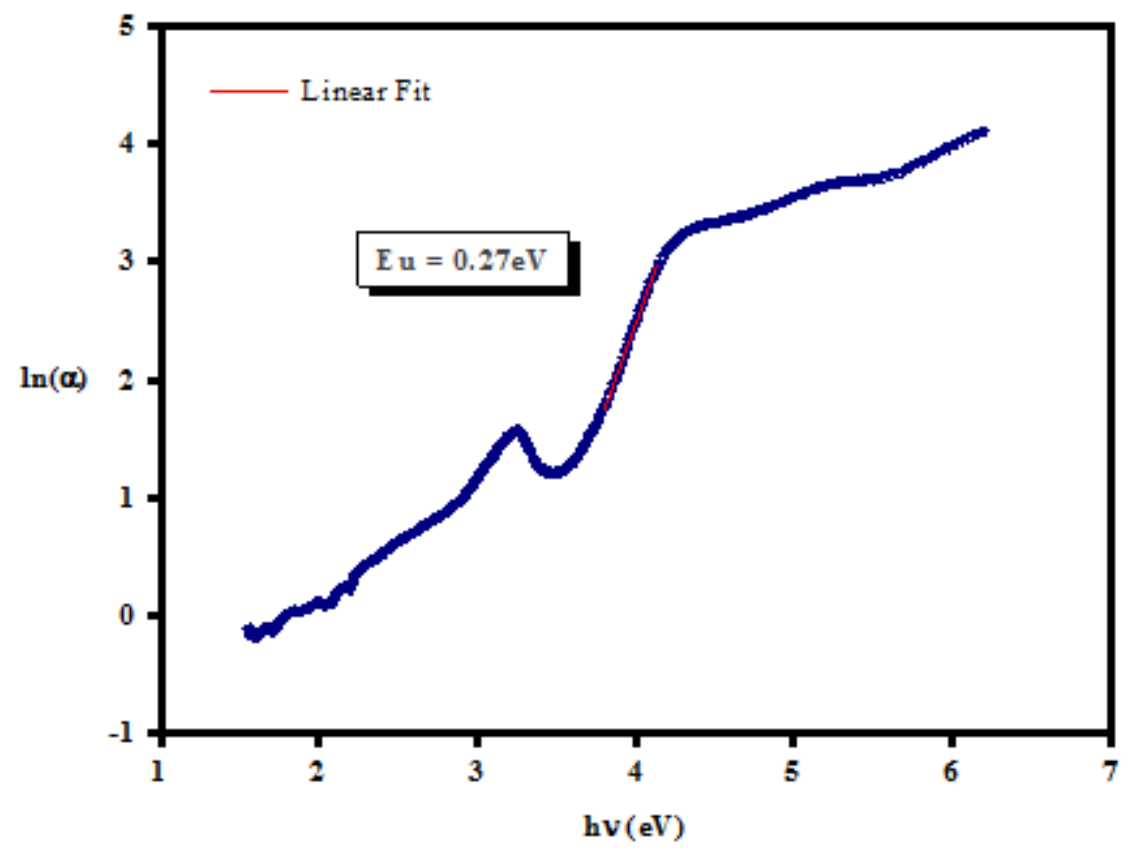

Figure 9

Plot of $\mathrm{Ln}(\mathrm{a})$ versus (hv) of the $[\mathrm{P}(\mathrm{C} 4 \mathrm{H} 9) 4] 2 \mathrm{SnCl} 6$ compound.

Fig.10

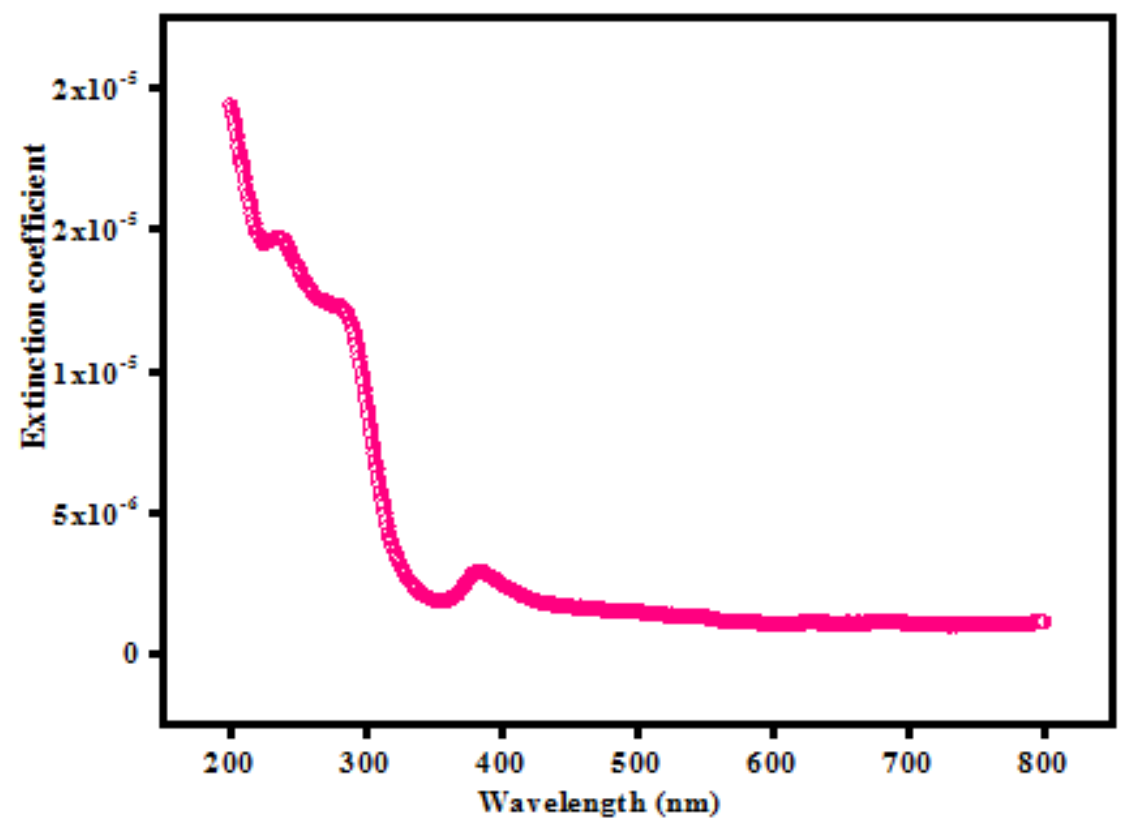


Figure 10

Dispersion curve of extinction coefficient $k$ as a function of wavelength. 